\title{
Targeting the Bcl-2-regulated apoptosis pathway by BH3 mimetics: a breakthrough in anticancer therapy?
}

\author{
V Labi ${ }^{1}, \mathrm{~F}$ Grespi ${ }^{1}$, F Baumgartner ${ }^{1}$ and A Villunger ${ }^{*}, 1$
}

Induction of apoptosis in tumor cells by direct activation of the Bcl-2-regulated apoptosis pathway by small molecule drugs carries high hopes to overcome the shortcomings of current anticancer therapies. This novel therapy concept builds on emerging insights into how Bcl-2-like molecules maintain mitochondrial integrity and how pro-apoptotic BH3-only proteins lead to its disruption. Means to unleash the pro-apoptotic potential of BH3-only proteins in tumor cells, or to bypass the need for BH3only proteins by directly blocking possible interactions of Bcl-2-like pro-survival molecules with Bax and/or Bak, constitute interesting options for the design of novel anticancer therapies. For the optimization and clinical implementation of these novel anticancer strategies, a detailed understanding of the role of individual BH3-only proteins in cell death signaling in healthy cells and during tumor suppression is required. In this review, we will touch on the latest findings on BH3-only protein function and attempts to define the molecular properties of the so-called 'BH3 mimetics,' a novel class of anticancer agents, able to prompt apoptosis in tumor cells, regardless of their $\mathrm{p} 53$ or Bcl-2 status.

Cell Death and Differentiation (2008) 15, 977-987; doi:10.1038/cdd.2008.37; published online 28 March 2008

Modern anticancer strategies finally move away from the use of crude nonspecific cytotoxic agents toward the application of rationally designed drugs that inhibit well-defined targets in specific cellular signaling pathways involved in tumorigenesis. A key assumption of many of these novel strategies is that the maintenance and progression of cancers are critically dependent on resistance of transformed cells to undergo cell death. During neoplastic transformation, cancer cells are usually selected to gain the ability to survive otherwise deadly cellular and genetic changes. These alterations can be caused by oncogenic stress, impaired cell cycle arrest and/ or DNA damage repair functions, genomic instability, telomere erosion, trophic factor deprivation or loss of adhesion.

The link between impaired apoptosis and tumorigenesis became apparent when the antiapoptotic protein Bcl-2 (B-cell lymphoma 2) was initially described as a potential oncogene more than 20 years ago. Bcl-2 was found overexpressed in $90 \%$ of human follicular lymphoma and $75 \%$ of all cases were harboring the characteristic $\mathrm{t}(14 ; 18)$ chromosome translocation that juxtaposes the $b c l-2$ gene to the immunoglobulin heavy chain $(I G H)$ locus (Adams and Cory ${ }^{1}$ and citations therein). Seminal work by Vaux et al. ${ }^{2}$ identified Bcl-2 as a survival factor shortly thereafter. Genetic analysis in mice overexpressing a bcl-2 transgene further provided strong evidence that aberrant expression of $\mathrm{Bcl}-2$, although being poorly oncogenic on its own, facilitates onset of malignant disease, once the cell cycle machinery is deregulated by aberrant expression of oncogenes such as $c$-myc. ${ }^{1}$ Consistently, Bcl-2 or related pro-survival family members were found frequently overexpressed in many human tumor types identifying Bcl-2 and its subsequently discovered homologs as promising candidates for therapeutic intervention.

Mammals control tissue homeostasis by apoptosis, which allows removal of damaged, infected or otherwise unwanted cells. Therefore, the apoptosis machinery acts as a barrier against cancer but is also rate limiting for the efficacy of anticancer therapy.

Two major pathways can lead to apoptosis in mammalian cells. The stress-induced 'intrinsic' or mitochondrial cell death pathway, regulated by the $\mathrm{Bcl}-2$ family, is more ancient and evolutionarily conserved from worms to mammals than the death receptor (DR)-induced or 'extrinsic' cell death pathway, which co-evolved with the establishment of adaptive immunity in vertebrates. The extrinsic pathway is induced when DRs, members of the TNF (tumor necrosis factor) receptor $(R)$ family (e.g. CD95, TRAIL-R or TNF-R), are engaged by their cognate ligands, belonging to the TNF family (e.g. FasL, TRAIL or TNF). Subsequently, on the cytosolic side of the DR a protein complex called DISC, (death-inducing signaling complex), consisting of the DR, an adapter protein (e.g. FADD in case of CD95) and proteases of the caspase family, that is, pro-caspase-8 or -10 in humans, is formed. Within this

\footnotetext{
${ }^{1}$ Division of Developmental Immunology, Department of Biocenter, Innsbruck Medical University, Innsbruck, Austria

${ }^{*}$ Corresponding author: A Villunger, Division of Developmental Immunology, Biocenter, Innsbruck Medical University, Fritz-Pregl-Str.3, Innsbruck A-6020, Austria. Tel: + 435129003 70380; Fax: + 435129003 73960; E-mail: andreas.villunger@i-med.ac.at

Keywords: apoptosis; Bcl-2 protein family; $\mathrm{BH} 3-$ only proteins; $\mathrm{BH} 3$ mimetics; cancer

Abbreviations: Bad, Bcl-2 antagonist of cell death; Bak, Bcl-2 antagonist/killer; Bax, Bcl-2-associated protein X; Bcl-2, B-cell lymphoma 2; Bcl-x, Bcl-2-related protein $\mathrm{X}$; BH, Bcl-2 homology; Bid, Bcl-2 interacting domain death agonist; Bik, Bcl-2 interacting killer-like; Bim, Bcl-2 interacting mediator of cell death; Bmf, Bcl-2-modifying factor; DR, death receptor; Hrk, harakiri; IAP, inhibitor of apoptosis protein; Puma, p53-upregulated modulator of apoptosis; TNF, tumor necrosis factor; XIAP, X-linked inhibitor of apoptosis protein

Received 09.1.08; revised 03.3.08; accepted 03.3.08; Edited by C Borner; published online 28.3.08
} 
complex, pro-caspase- 8 or -10 is activated by dimerization leading to their full activation, which, in turn, allows processing of the effector caspase-3, -6 and -7 by proteolytic cleavage. Similarly, apoptosis along the intrinsic pathway, regulated by the Bcl-2 family and mitochondria (discussed in more detail below), also culminates in the activation of these caspases. Once active, effector caspases provoke cellular destruction by cleaving hundreds of proteins within the cell. ${ }^{3}$

Although initially considered as a potent anticancer drug, TNF can only be applied in limited number of clinical settings due to its strong systemic side effects, including endothelial damage and liver cytotoxicity. However, recombinant TRAIL or humanized therapeutic agonistic antibodies targeting TRAIL-RI and/or TRAIL-RII are promising candidates for (combinatorial) anticancer therapy due to their selectivity to trigger apoptosis preferentially in transformed cells and are currently being investigated for their in vivo potency in phase II clinical trials. Another example aiming to exploit the extrinsic apoptosis pathway for anticancer therapy is the use of CD95Ig fusion proteins for its suitability to prevent FasL-mediated graft versus host disease while preserving graft versus leukemia effects. In addition, a modified version of FasL, which does not cause liver cytotoxicity, is currently under way to enter clinical trials (for recent detailed reviews see Fesik ${ }^{4}$ and Kassahn et al. ${ }^{5}$ ).

Both the extrinsic and intrinsic apoptosis pathways converge at the level of effector caspase activation, identifying these molecules as 'ideal' drug targets. Caspase activity is regulated by certain members of the inhibitor of apoptosis protein (IAP) family, most potently by XIAP (X-linked IAP), which is able to bind to and inactivate caspase- $-9,-3$ and -7 . This interaction is neutralized by IAP antagonists such as SMAC/DIABLO, which is released from mitochondria during apoptosis induction. Although other members of the IAP family including clAP1, clAP2 or ML-IAP have also been shown to block cell death, the molecular basis of inhibition is less clear. However, many of these IAP family proteins have been implicated in the pathogenesis and/or drug resistance of a number of malignant diseases, including melanoma, hepatocellular carcinomas or pancreatic cancer. ${ }^{6}$ At least three companies developed synthetic compounds targeting IAP-caspase interaction sites. Surprisingly, latest studies revealed that these SMAC mimetics trigger tumor cell death by initiating an autocrine TNF loop rather than by directly activating caspases. ${ }^{7-9}$ Since systemic application of TNF is known to cause severe side effects, it will be interesting to see how tolerable and beneficial these compounds are when used to treat cancers in preclinical in vivo models. Short-term lowlevel autocrine TNF production and/or sensitization to TNF signaling, triggered by SMAC mimetics, may be much better tolerated than systemic administration of this cytokine, hopefully paving the way for clinical trials.

\section{Cell Death Signaling Regulated by the Bcl-2 Family: a Simplified View}

Whether a cell continues to live in response to diverse forms of stress or undergoes apoptosis along the intrinsic signaling pathway is largely determined by the complex interplay between individual members of the $\mathrm{Bcl}-2$ protein family that can either promote or prevent apoptosis. The five known survival-promoting family members $\mathrm{Bcl}-2, \mathrm{Bcl}-\mathrm{x}_{\mathrm{L}}(\mathrm{Bcl}-2-$ related protein $\mathrm{x}_{\mathrm{L}}$ ), $\mathrm{Bcl}-\mathrm{w}, \mathrm{Mcl}-1$ and $\mathrm{A} 1$ share four $\mathrm{Bcl}-2$ homology $(\mathrm{BH})$ domains $(\mathrm{BH} 1-\mathrm{BH} 4)$ among each other, with the exception of $\mathrm{Mcl}-1$ that contains only three of these domains. All these proteins are critical for cell survival, since loss of any of them causes premature cell death of certain cell types. Bcl-2 appears highly critical for the survival of mature lymphocytes and melanocytes, whereas neurons and erythroid progenitors depend on the presence of $\mathrm{BCl}-\mathrm{x}_{\mathrm{L}}$ as myeloid progenitors, lymphocytes and hematopoietic stem cells do on $\mathrm{Mcl}-1$ (for a more detailed review see Youle and Strasser ${ }^{3}$ and references therein). Consistently, overexpression of Bcl-2 pro-survival molecules is associated with prolonged (tumor) cell survival and drug resistance in a number of model systems, but more importantly, also in tumor patients.

The pro-apoptotic Bcl-2 family members can be divided into two classes: the $\mathrm{Bax}$ (Bcl-2-associated protein $\mathrm{X}$ )-like proteins (Bax, Bak (Bcl-2 antagonist/killer) and Bok) that contain three $\mathrm{BH}$ domains (also called $\mathrm{BH} 123$ or multi-domain pro-apoptotic $\mathrm{Bcl}-2$ proteins) and the $\mathrm{BH}$-only proteins. The latter include Bim (Bcl-2 interacting mediator of cell death), Bid (Bcl-2 interacting domain death agonist), Puma (p53-upregulated modulator of apoptosis), Noxa, Bmf (Bcl-2-modifying factor), Bad (Bcl-2 antagonist of cell death), Hrk (harakiri) and Bik (Bcl-2 interacting killer-like) that are unrelated in their sequence to each other or other Bcl-2 family members with the exception of the $\mathrm{BH} 3$ domain. The $\mathrm{BH} 3$ domain forms an amphipathic alpha helix of about 24 residues that enables binding to a hydrophobic groove on the surface of pro-survival $\mathrm{Bcl}-2$ molecules, formed by amino acids contained in the $\mathrm{BH} 1$, $\mathrm{BH} 2$ and $\mathrm{BH} 3$ domains, thereby mediating protein-protein interaction. $^{3}$ For the pro-apoptotic function of BH3-only proteins, the multi-domain proteins Bax and Bak are absolutely essential. ${ }^{10}$ Whereas loss of either Bax or Bak has only little effect on apoptosis induction in most cell types, combined deficiency of both proteins causes perinatal lethality in mice and renders cells highly resistant to overexpression of $\mathrm{BH} 3-$ only proteins as well as to a broad range of apoptotic stimuli triggering the intrinsic cell death pathway. ${ }^{11}$

Molecular action of BH3-only proteins. It has been anticipated for a long time that all Bcl-2 pro-survival proteins can substitute for each other in inhibiting cell death in response to genotoxic stress and that overexpression of any given BH3-only protein can kill cells in a rather nonspecific manner. However, recent biochemical and genetic evidence suggest that $\mathrm{BH} 3$-only proteins act only in a much more specific way to neutralize the prosurvival function of $\mathrm{Bcl}-2$-like molecules. Interestingly, the combination of $\mathrm{BH} 3$-only proteins that is required to achieve that differs, depending on the apoptotic stimulus that hits the cell, as well as on the expression pattern of antiapoptotic $\mathrm{Bcl}-2$ molecules. ${ }^{12}$

Bim and Puma, for example, can engage all pro-survival $\mathrm{Bcl}-2$ proteins with comparable binding affinities and are therefore potent killers. In contrast, other BH3-only family members target selectively only subsets of pro-survival $\mathrm{Bcl}-2$ proteins, for example, Bad or Bmf can only counteract the 
function of $\mathrm{Bcl}-2, \mathrm{Bcl}-\mathrm{x}_{\mathrm{L}}$ or $\mathrm{Bcl}-\mathrm{w}$, whereas Noxa exclusively counteracts $\mathrm{Mcl}-1$ and $\mathrm{A} 1,{ }^{13}$ and therefore possesses only weak or no killing activities on its own (Figure 1a). On the basis of these observations, one can predict that a normal or malignant cell that expresses $\mathrm{Bcl}-2$ and $\mathrm{Mcl}-1$ can only be killed by Bim or Puma but not by activation of Bad or Bmf, which fail to neutralize $\mathrm{Mcl}-1$. Alternatively, combining two 'weak killers' targeting the whole spectrum of Bcl-2 prosurvival molecules, such as Bad and Noxa, should potently induce apoptosis in such a cell and this hypothesis has been confirmed in a number of experimental settings. ${ }^{13,14}$

In an alternative model, called the 'direct activator' model, BH3-only proteins are further split up into two groups (Figure 1b). The 'direct activators' Bim, tBid (the activated truncated form of Bid) and maybe also Puma, are thought to directly bind to Bax/Bak as well as pro-survival family members, whereas all other BH3-only proteins, that is, Bad, Hrk, Bik, Bmf and Noxa, are only able to bind to pro-survival a

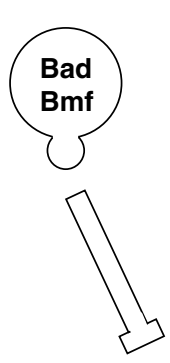

Affinity mode

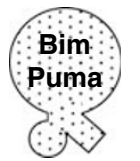

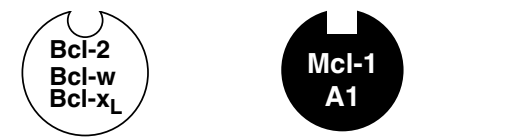
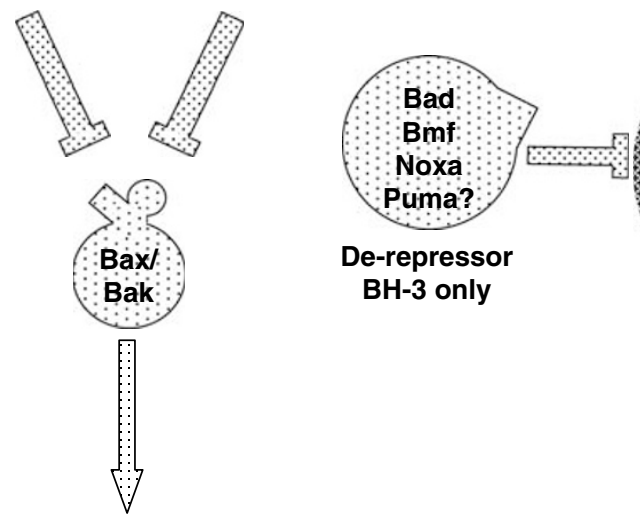

\section{De-repressor $\mathrm{BH}-3$ only}

Oligomerization

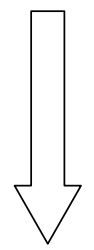

Multi-domain
Pro-apoptotic

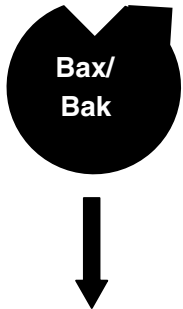

Multi-domain Antiapoptotic
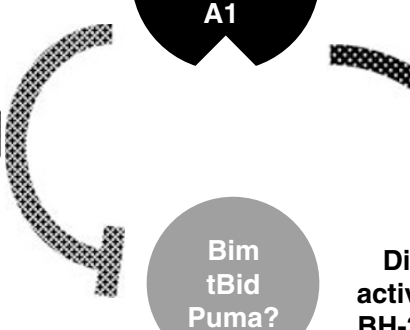

Direct activators BH-3 only

\section{APOPTOSIS}

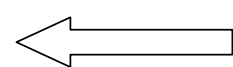

Oligomerization

Figure 1 Possible modes of BH3-only protein function. The affinity model (a) suggests that BH3-only proteins possess different capacities to interact with $\mathrm{Bcl}-2$ prosurvival homologs. Bim and Puma can engage all pro-survival Bcl-2 proteins with comparable affinities and are therefore potent killers. Other $\mathrm{BH} 3-$ only family members target selectively only subsets of pro-survival Bcl-2 proteins, for example, Bad or Bmf can counteract the function of Bcl-2, Bcl- $\mathrm{x}$ L or Bcl-w, whereas Noxa can only counteract Mcl-1 and A1. To trigger cell death, all Bcl-2 survival proteins expressed in a given cell must be neutralized to relieve Bak and/or Bax from sequestration by these proteins that promotes their oligomerization triggering apoptosis. In the 'direct activator' model (b), BH3-only proteins are split-up into two groups. The 'direct activators' Bim and tBid (and maybe Puma) are thought to directly bind to Bax/Bak as well as pro-survival family members, whereas all other BH3-only proteins, that is, Bad, Hrk, Bik, Bmf and Noxa, are only able to bind to pro-survival Bcl-2 family members and are considered to act as 'sensitizers.' In this model, it is assumed that stress stimuli activate mainly sensitizer BH3only proteins that subsequently compete with Bim and tBid for binding to Bcl-2 proteins leading to their displacement from antiapoptotic proteins. Free Bim or tBid then in turn directly bind and activate Bax or Bak inducing their oligomerization thus leading to apoptosis 
Bcl-2 family members and are considered to act as 'sensitizers.' 15,16 In this model, it is assumed that stress stimuli activate mainly sensitizer BH3-only proteins that subsequently compete with Bim and tBid for binding to $\mathrm{Bcl}-2$ proteins leading to their displacement from antiapoptotic proteins. Free Bim or tBid then in turn directly binds and activates Bax or Bak inducing their oligomerization and subsequent permeabilization of the outer mitochondrial membrane, caspase activation and cell death. ${ }^{15,16}$ This model predicts, however, that the sensitizer $\mathrm{BH} 3$-only proteins must be highly competitive, either due to higher binding affinities to Bcl-2 and homologs, or vast stoichiometric excess over Bim, Puma or tBid. Direct interaction between Bax and Bim or Bid, however, has so far never been confirmed in response to cell death initiation at the endogenous protein level, leading to the proposition of a 'hit and run' mode of action.

Recent evidence provided by Willis et al. ${ }^{14}$ identified a putative Achilles heel of the direct activation model by demonstrating that mice that lack Bim and Bid do not resemble the Bax/Bak double knockout phenotype and that additional knock down of Puma in cells lacking Bim and Bid does not provide protection from $\mathrm{BH}$-only protein-induced apoptosis. In addition, tBid and $\mathrm{Bim}_{\mathrm{S}}$ proteins bearing mutations within their $\mathrm{BH} 3$ domains that prevent binding to Bax, but not Bcl-2, killed cells as efficiently as the relevant wild-type proteins.

Taken together, we have to assume that $\mathrm{BH} 3$-only proteins kill normal as well as malignant cells by neutralizing the cell-typespecific pool of pro-survival Bcl-2 family members, which usually prevent the assembly of Bax and/or Bak oligomers (Figure 1).

\section{Targeting the Bcl-2 Family in Cancer Therapy}

Antisense-based strategies. Pathologic overexpression of pro-survival Bcl-2 family proteins was frequently observed in many tumor types and identified Bcl-2 and/or $\mathrm{Bcl}-\mathrm{x}_{\mathrm{L}}$ as possible drug targets in the 1990s. However, since Bcl-2 family members are intracellular proteins that do not show any intrinsic catalytic function, targeting by antibodies or small molecule drugs were no feasible options, fostering attempts to interfere with mRNA expression levels by antisense oligonucleotide (ASO)-based strategies. ${ }^{17}$ ASOs are single-stranded chemically modified oligodeoxynucleotides (18-21 mer) that target complementary mRNA for RNaseH-mediated degradation after sequencespecific hybridization and generation of a RNA-DNA heteroduplex, but may exert their effects in part via their immune-modulatory properties (e.g. by TLR activation). ${ }^{17}$ Oblimersen (Genasense $^{\mathrm{TM}}$ ) is a 18-bp phosphorothioate oligonucleotide targeting the first six codons of $b c l-2$ mRNA and has been evaluated for suitability of the treatment of a number of tumors, including small cell lung cancer (SCLC), ${ }^{18}$ prostate cancer, $^{19}$ renal cell carcinoma, ${ }^{20}$ myeloid leukemia $^{21}$ as well as non-Hodgkin lymphomas. ${ }^{22}$ This compound is already well advanced in clinical trials for the treatment of refractory CLL, ${ }^{23}$ multiple myeloma ${ }^{24}$ and melanoma. ${ }^{25}$ Knowing the molecular basics of how Bcl-2like molecules preserve survival and how $\mathrm{BH} 3$-only proteins kill cells immediately highlight the limitations of antisense- based strategies that can only target one, or at best, two highly homologous proteins at a time ${ }^{26}$ (see above and Figure 1). However, in combination with conventional anticancer treatments Oblimersen may achieve clinical benefits. For example, a recent publication reported promising results regarding the addition of Oblimersen to fludarabine plus cyclophosphamide for the treatment of patients with relapsed or refractory CLL. ${ }^{23}$

Natural and chemical inhibitors of Bcl-2. A number of natural compounds were identified as potential $\mathrm{Bcl}-2$ inhibitors over the past years. ${ }^{27}$ Antimycin $A$, a streptomyces-derived inhibitor of ubiquinone-cytochrome $c$ oxidoreductase at the mitochondrial respiration chain, was reported to promote cell death by binding to Bcl-2. A 2methoxy derivative, no longer inhibiting mitochondrial respiration, was still able to kill $\mathrm{Bcl}-\mathrm{x}_{\mathrm{L}}$ overexpressing cells. ${ }^{28}$ Chelerythrine, a plant alkaloid originally identified in a high-throughput screen for PKC inhibitors, was shown to disrupt $\mathrm{Bcl}-\mathrm{x} / \mathrm{Bax}$ complexes in in vitro experiments. ${ }^{29}$ In addition, gossypol and apogossypol, derivatives of the cottonseed extract which was first described almost a 100 years ago, ${ }^{30}$ were discussed to exert their function by induction of apoptosis due to inhibition of Bcl-2. ${ }^{31}$ Another compound, the harmine-derivative compound-6, was suggested to promote cell death by inhibiting transcription of $\mathrm{Bcl}-2$, but may actually do so by influencing the transcription of many genes. ${ }^{32}$

All these compounds, including the non-peptidic chemical compounds $\mathrm{HA} 14-1^{33}$ and $\mathrm{BH} 3 \mathrm{I}-\mathrm{I}^{34}$ that were generated based on computer modeling onto the $\mathrm{Bcl}-2$ structure, were shown subsequently to kill cells largely in a Bax/Bakindependent manner, clearly demonstrating that their cytotoxic effect was not solely due to specific inhibition of, or interaction with $\mathrm{Bcl}-2$ or its homologs. ${ }^{35}$ This, however, does not exclude the possibility that these compounds may prove useful for the treatment of certain cancers, since they potently kill tumor cells in various experimental settings. The interaction of these drugs with different Bcl-2 family members may even strongly contribute to their effects, but necrosis, ${ }^{36}$ release of AIF, ${ }^{37}$ the induction of autophagy ${ }^{38}$ or enforced metabolic changes ${ }^{39}$ may all contribute to their antineoplastic potential. Therefore, a more detailed analysis of their molecular mode of action is urgently needed.

More selective in this regard appears to be the design and synthesis of the so-called hydrocarbon-stapled $\mathrm{BH} 3$ helices, $\mathrm{BH} 3$ domain peptides modified to become cell permeable and protease resistant. These stapled peptides called 'stabilized alpha helix of Bcl-2 domains' (SAHBs) showed increased helicity in solution, when compared with unmodified $\mathrm{BH} 3$ peptides that appear to exist as random coils, and bind with high affinity to the multi-domain $\mathrm{Bcl}-2$ member binding pocket. A Bid-based stapled BH3 peptide $\left(\mathrm{SAHB}_{\mathrm{A}}\right)$ showed cytotoxicity against a panel of tumor cell lines in the nanomolar range and delayed growth of human leukemia in a xenotransplant model. ${ }^{40}$ Very little information about their effects on healthy cells or their molecular mode of action is currently available in the public domain. Direct induction of Bax oligomerization has been proposed to account for the ability of $\mathrm{SAHB}_{\mathrm{A}}$ to trigger cell death. ${ }^{41}$ 
BH3 mimetics. Overexpression of pro-survival Bcl-2 family members is a common feature of many tumors and therefore, drugs mimicking the function of their proapoptotic counterparts, the $\mathrm{BH}$-only proteins, hold large promise as alternative anticancer strategies. The advantage of this therapeutic approach is the possibility to circumvent the need to induce expression of $\mathrm{BH}$-only proteins that is often compromised in tumor cells either due to gene ablation (e.g. Bim in mantle cell lymphoma), epigenetic silencing of $\mathrm{BH} 3-$ only protein gene promoters as described for the bim gene in renal cell carcinoma and melanoma or, even more frequently, due to inactivation of the p53 pathway that usually triggers activation of Puma and Noxa. ${ }^{42}$ Importantly, under all these circumstances, the core executioners of apoptosis, that is, caspases, are still present and could be used to drive apoptosis of tumor cells, once kick started. Therefore, lots of effort was put into defining compounds mimicking the action of BH3-only proteins, and non-peptidic 'BH3 mimetics' were rationally designed based on structural information gathered on protein-protein interactions within the Bcl-2 family.

The first non-peptidic 'BH3 mimetic,' based on a helical peptide-like terphenyl scaffold that showed low nanomolar affinity for the hydrophobic groove of $\mathrm{Bcl}-\mathrm{x}_{\mathrm{L}}$, was reported in 2002. ${ }^{43}$ Meanwhile additional compounds including the benzenesulfonyl derivative $\mathrm{TW}-37,{ }^{44}$ a putative $\mathrm{BH} 3$ mimetic designed on the structural basis of gossypol, Obatoclax (GX015-070) from GeminX Pharmaceuticals or A-385358 from Abbott, have been tested in preclinical studies. The Abbott compound showed low single-agent efficacy but enhances the cytotoxic activity of a number of DNA-damaging anticancer agents as well as paclitaxel. ${ }^{45}$ Obatoclax showed promising in vitro efficacy against non-SCLC, mantle cell lymphoma as well as multiple myeloma cells but failed to exhibit efficacy in tumor xenotransplant models in vivo. ${ }^{46-48}$ TW-37 reportedly induced apoptosis in PC3 prostate cancer cells, diffuse large B-cell lymphoma cells (DLBCLs), acute lymphatic leukemia (ALL) and melanoma cells in vitro as well as in DLBCL and melanoma xenotransplant models in vivo. $^{44,49,50}$ Both compounds appear to increase the efficacy of a range of conventional anticancer agents. Although high binding affinities of these compounds to certain pro-survival Bcl-2 family members have been reported, for example, TW-37 is able to bind $\mathrm{Bcl}-2, \mathrm{Bcl}-\mathrm{x}_{\mathrm{L}}$ and $\mathrm{Mcl}-1$ in the nanomolar or near nanomolar range, ${ }^{44}$ little information on their molecular mode of action is currently available. The most studied and certainly promising $\mathrm{BH} 3$ mimetic to date is $\mathrm{ABT}$ 737 developed by Abbott, now joining forces with Genentech on this project.

ABT-737: mode of action. ABT-737 is a cell permeating, synthetic $\mathrm{BH} 3$ mimetic that was designed by Oltersdorf et al. ${ }^{51}$ using a NMR structure-based approach to target the $\mathrm{BH} 3-$ binding groove on $\mathrm{BCl}-\mathrm{x}_{\mathrm{L}}$. It binds with high affinity in the subnanomolar range to $\mathrm{Bcl}-2, \mathrm{Bcl}-\mathrm{x}_{\mathrm{L}}$ and $\mathrm{Bcl}-\mathrm{w}\left(K_{\mathrm{i}}<1 \mathrm{nM}\right)$ even in the presence of human serum but only weakly to Mcl1 and BFL-1/A1 $\left(K_{\mathrm{i}}>460 \mathrm{nM}\right)$, resembling the binding affinities of the BH3-only protein Bad. Although being unable to trigger cytochrome $c$ release on its own, ABT-737 efficiently antagonized the $\mathrm{Bcl}-2-$ or $\mathrm{Bcl}-\mathrm{x}_{\mathrm{L}}$-mediated inhibition of cytochrome $c$ release from isolated mitochondria triggered by application of recombinant myristylated Bid. Subsequently, it was shown that this effect requires the presence of Bax or Bak, suggesting that ABT-737 can engage both multi-domain pro-apoptotic proteins to trigger cell death. Taken together, this indicates that ABT-737 acts as a 'sensitizer' BH3 mimetic that requires the presence of 'direct activator' $\mathrm{BH}$-only proteins to trigger cytochrome $c$ release, ${ }^{51}$ according to one model of $\mathrm{BH} 3-$ only protein function (Figure 1). Consistent with this hypothesis, it was reported that mouse $T$ lymphocytes lacking Bim are less susceptible to the cytotoxic action of ABT-737.52

Konopleva et al. ${ }^{53}$ observed efficient cytochrome $c$ release from ABT-737-treated mitochondria isolated from $\mathrm{HL}-60$ acute myeloid leukemia (AML) cells. They report that in $\mathrm{HL}$ 60 cells ABT-737 effectively disrupts $\mathrm{Bcl}-2 / \mathrm{Bax}$ heterodimeric complexes and induces a conformational change in Bax, indicative of its activation. Furthermore, knock down of Bak, but not Bim, did abrogate ABT-737-induced apoptosis, suggesting that its direct activator function is not required for killing. They also provide evidence that in MEF, ABT-737 may require the presence of both, Bax and Bak, for efficient killing, since cells lacking either molecule were no longer responsive to the compound. ${ }^{53}$ van Delft et al., ${ }^{35}$ however, reported in a parallel study that even wild-type MEFs are poor responders and demonstrated that either Bax or Bak can mediate killing by ABT-737, once Mcl-1 is inactivated, for example, by Noxa expression or when its levels are reduced by cytokine deprivation or inhibition of MAPK signaling. Consistent with the study by Konopleva, ABT-737 was found to induce a conformational change in Bax. Taken together, these data suggest that the initially reported observation that ABT-737 can engage Bax and/or Bak to kill cells are correct.

It has been reported that in certain tumor cells that overexpress $\mathrm{Bcl}-2$, Bim is already found associated with $\mathrm{Bcl}-$ 2 at mitochondria. ${ }^{54}$ This may be due to constant oncogenic stress causing $\mathrm{BH} 3-$ only protein activation that selects for $\mathrm{Bcl}-2$ overexpression to counterbalance BH3-only protein activation (a process often also termed 'Bcl-2-addiction'). It has been discussed that such tumor cells are in a 'primed' state for apoptosis, and it was speculated that 'sensitizer' $\mathrm{BH} 3-$ only proteins such as Bad or Bmf, or a compound such as ABT-737, should be sufficient to trigger cell death directly by releasing Bim from Bcl-2. ${ }^{54}$ In fact, evidence has been presented that in primary B-CLL cells, follicular lymphoma samples and some multiple myeloma cell lines, ABT-737 kills by releasing $\mathrm{Bim}$ from sequestration by $\mathrm{Bcl}-2$ triggering subsequent oligomerization of Bax and Bak. In addition, partial knock down of Bim reduced the sensitivity of L363 myeloma cells to ABT-737. ${ }^{54}$ All these observations are consistent with a requirement for a direct activator protein to kill tumor cells by ABT-737. However, caution is needed in the interpretation of such results since knock down of Bim in tumor cells or genetic loss of Bim in lymphocytes may simply cause a relative increase in the pool of freely available $\mathrm{Bcl}-2$ prosurvival homologs that can sequester more activated Bax and/or Bak. Hence, ABT-737 will be less efficient in such cells. If correct, this 'resistance' phenotype can simply be overcome by increasing the dose of ABT-737.

Consistent with the idea that $\mathrm{BH}$-only proteins or bona fide mimetics kill cells primarily by neutralizing the total pool of all 
$\mathrm{Bcl}-2$ pro-survival molecules expressed in a given cell type, ABT-737 can potently trigger cytochrome $c$ release in mouse liver mitochondria or MEF devoid of the direct activator $\mathrm{BH} 3-$ only proteins $\mathrm{Bim}$ and Bid. ${ }^{14}$ This indicates that once all $\mathrm{Bcl}-2$ homologs residing at the mitochondria in a particular cell type are neutralized by a stimulus-dependent combination of $\mathrm{BH}$ only proteins cell death can proceed.

The question whether ABT-737 exclusively kills cells by inducing apoptosis along the mitochondrial pathway to apoptosis (Figure 2), however, cannot be clearly answered yet. Recent observations suggested that ABT-737 also potently disrupts the interaction of $\mathrm{Bcl}-2$ or $\mathrm{Bcl}-\mathrm{x}_{\mathrm{L}}$ with Beclin-1 under certain experimental conditions, thereby promoting autophagy. ${ }^{55}$ Therefore, it is formally possible that autophagy may contribute to the antineoplastic effects of ABT-737, if drug treatment culminates in autophagic tumor cell death. Since the predominant physiological role of autophagy is the promotion of cell survival in response to nutrient deprivation or cellular damage, this phenomenon may also contribute to drug resistance phenotypes, warranting further investigations into this issue (Figure 2).

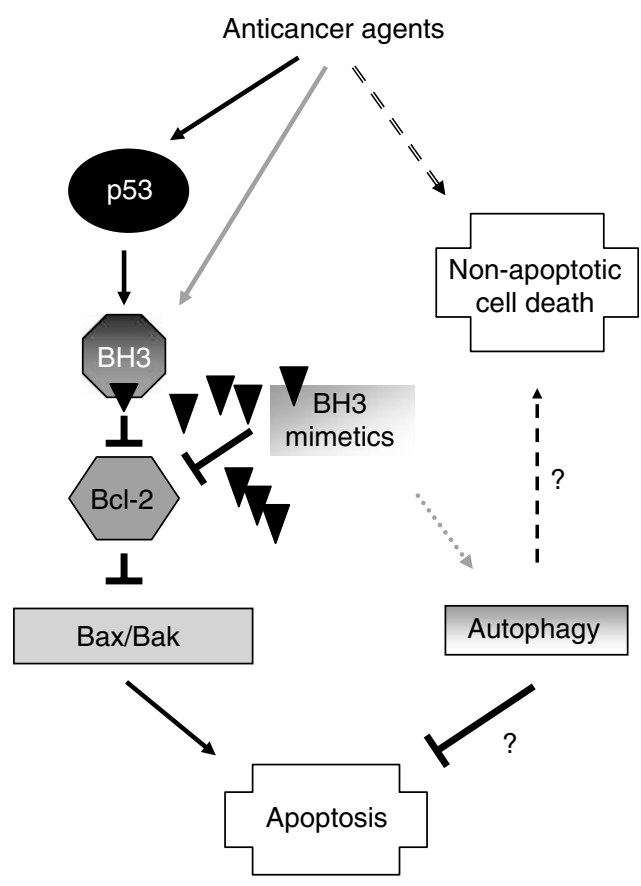

Figure 2 BH3 mimetics trigger tumor cell death by neutralizing Bcl-2 homologs. Many anticancer agents promote apoptosis predominantly by the activation of certain $\mathrm{BH} 3-$ only proteins. This can be achieved by enforced $\mathrm{BH} 3$-only protein gene transcription, for example via activation of p53 such as in the case of Puma or Noxa, or by promoting post-translational modification and/or protein stabilization, as shown for Bim or Bmf. BH3 mimetics circumvent the need for these processes that are often impaired or blocked in tumor cells (e.g. due to inactivation of the p53 pathway, hyperactivation of oncogenes, overexpression of pro-survival $\mathrm{Bcl}-2$ family members) and trigger apoptosis by neutralizing pro-survival $\mathrm{Bcl}-2$ homologs directly. $\mathrm{BH} 3$ mimetics may also trigger autophagy in certain cell systems. This phenomenon may contribute or compromise the antineoplastic effects of Bcl-2 inhibitors, depending on whether this leads to autophagic cell death or allows cell survival. Some anticancer agents can also cause non-apoptotic cell death of tumor cells, prompting necrosislike morphology or trigger expression of death receptors, facilitating apoptosis (not shown or discussed here)

\section{Pre-clinical Data on ABT-737}

A significant number of studies have evaluated the merit of ABT-737 in triggering apoptosis in cancer cells and cell lines ex vivo (Table 1). ABT-737 shows cytotoxic effects as a single agent on primary patient-derived follicular lymphoma cells and B-CLL cells. Only weak activity against various solid tumor cell lines was reported but SCLC cells proved to be relatively sensitive in single-agent experiments. ABT-737 potently enhanced the cytotoxicity of paclitaxel against a non-SCLC (NSCLC) cell line by a factor of $4 .^{51}$ Primary AML cell lines and patient blasts were reported to be highly sensitive to the mimetic, whereas normal peripheral blood mononuclear cells (PBMCs) proved largely resistant. ${ }^{53}$ As effective cancer therapy has to target cancer stem cells for long-term success, it is of special interest that AML stem cells seem to be highly sensitive toward ABT-737 treatment. Two out of six patent-derived AML samples showed complete deletion of cancer stem cells after ABT-737 treatment, one of them being highly resistant to Ara- $C$ treatment. Although the $\mathrm{OCI}-\mathrm{AML} 3$ cell line is relatively resistant to $\mathrm{ABT}-737$ on its own, combined treatment with Ara-C or doxorubicine revealed synergistic effects on apoptosis induction. ${ }^{53}$

ABT-737 potently synergizes with the Abelson tyrosine kinase inhibitors Imatinib (Gleevec) or INNO-406 in killing human CML cells. ${ }^{62,63}$ Imatinib thereby exerts its proapoptotic effects mainly by inducing Bim and Bad. ${ }^{62}$ Interestingly, ABT can overcome the drug resistance of bcr-abl-transformed mouse leukemia cells lacking these $\mathrm{BH} 3-$ only proteins as well as in those overexpressing Bcl-2. ${ }^{62}$ This is of clinical relevance since $\mathrm{Bcl}-2$ overexpressing $\mathrm{Ph}^{+} \mathrm{CML}$ cells often show reduced sensitivity to Gleevec. ${ }^{70}$ The cytotoxic effects caused by inhibition of transforming tyrosine kinase activities by a number of agents including Gefitinib ${ }^{57}$ or Erlotinib, ${ }^{71}$ both targeting the EGFR kinase activity in epithelial tumors, such as NSCLC or Sunitinib, inhibiting the action of FLT-3 kinase carrying activating internal tandem duplication frequently found in AML patients, are strongly enhanced by the Abbott compound. ${ }^{60}$ All these kinase inhibitors trigger apoptosis by inducing transcription of the bim gene and presumably also by dephosphorylating Bim and Bad, that are already present in the tumor cells. ${ }^{57,62,72}$

In multiple myeloma, ABT-737 has been extensively tested and was shown to potently act as a single-agent drug on a number of cell lines, including glucocorticoid-resistant ones. $^{66-68}$ Additive effects in combination with standard therapeutics such as melphalan, glucocorticoids as well as the recently approved proteasome inhibitor bortezomib (PS341) were demonstrated in cell lines. ${ }^{68}$ However, others failed to observe synergy between ABT-737 and bortezomib. ${ }^{67}$ In primary patient-derived myeloma cells, however, the $\mathrm{BH} 3$ mimetic showed varying efficacy inducing apoptosis in the range from 20 to $90 \%$ of cells in one study, ${ }^{67}$ but failed to induce apoptosis in a significant portion of primary tumor cells in another report. ${ }^{66}$ An important information provided is that not only human PBMCs but also bone marrow-derived progenitors from myeloma patients are not affected in their colony-forming potential by the Bcl-2 inhibitor. ${ }^{67}$ Discrepancy exists between the studies whether survival signals provided 
Table 1 Preclinical data on ABT-737 efficacy in different tumor types

\begin{tabular}{|c|c|c|c|c|c|}
\hline \multirow[b]{3}{*}{ Tumor type } & \multicolumn{4}{|c|}{ ABT-737 efficacy } & \multirow[b]{3}{*}{ References } \\
\hline & \multicolumn{2}{|r|}{ Cell lines } & \multicolumn{2}{|c|}{ Primary tumor cells } & \\
\hline & Single agent & Combinatorial treatment with & Single agent & Combinatorial treatment with & \\
\hline SCLC & + & ND & ND & $\begin{array}{l}\text { Carboplatin } \\
\text { Etoposide }\end{array}$ & 51,56 \\
\hline NSCLC & - & $\begin{array}{l}\text { Gefitinib }^{a} \\
\text { Erlotinib }^{\mathrm{a}} \\
\text { Paclitaxel }^{\mathrm{b}}\end{array}$ & ND & ND & 57,58 \\
\hline Breast cancer & - & ND & ND & ND & 35 \\
\hline Cervical carcinoma & - & ND & ND & ND & 35 \\
\hline Colon cancer & - & Mcl-1 knockdown & ND & ND & 59 \\
\hline Bladder cancer & - & Mcl-1 knockdown & ND & ND & 59 \\
\hline Glioma & - & Mcl-1 knockdown & ND & ND & 59 \\
\hline AML & + & $\begin{array}{l}\text { Roscovitine } e^{c} \\
\text { PD98089 }^{d}\end{array}$ & + & $\begin{array}{l}\text { Ara-C } \\
\text { Sunitimib }\end{array}$ & $53,60,61$ \\
\hline CML & - & $\begin{array}{l}\text { Imatinib }{ }^{\mathrm{a}} \\
\text { INNO-406 }^{\mathrm{a}}\end{array}$ & ND & ND & $60,62,63$ \\
\hline CLL & ND & ND & + & ND & 51 \\
\hline DLBL/FL & + & ND & ND & ND & 64,65 \\
\hline Myeloma & + & ND & + & $\begin{array}{l}\text { Melphalan } \\
\text { Bortezomib } \\
\text { Dexamethasone }\end{array}$ & $54,66-68$ \\
\hline ALL & + & $\begin{array}{l}\text { L-ASP } \\
\text { Vincristine }^{\mathrm{b}} \\
\text { Dexamethasone Roscovitine }^{\mathrm{c}}\end{array}$ & ND & $\begin{array}{l}\text { ND } \\
\text { NDametnasone }\end{array}$ & 61,69 \\
\hline
\end{tabular}

ALL, acute lymphoblastic leukemia; AML, acute myelogenous leukemia; APL, acute promyelocytic leukemia; Ara-C, cytosine arabinoside; CLL, chronic lymphocytic leukemia; CML, chronic myelogenous leukemia; DLBL, diffuse large B-cell lymphoma; FL, follicular lymphoma; ND, not determined; NSCLC, non-small cell lung cancer; SCLC, small cell lung cancer ${ }^{a}$ Tyrosine kinase inhibitors ${ }^{b}$ Microtubule stabilizing agents ${ }^{\mathrm{C}}$ Inhibitor of cyclin-dependent kinases, e.g. Cdk-2 ${ }^{\mathrm{d}} \mathrm{MAP}$ kinase inhibitor ${ }^{\mathrm{L}}$-Asparaginase amidohydrase

Table 2 Assessing the in vivo efficacy of ABT-737

\begin{tabular}{|c|c|c|c|c|}
\hline \multirow[b]{2}{*}{ Tumor type } & \multicolumn{3}{|c|}{ ABT-737 efficacy } & \multirow[b]{2}{*}{ References } \\
\hline & Mouse model & Single agent & Combinatorial & \\
\hline SCLC cell lines H146, H1963 and others & Xenograft & $\begin{array}{l}\text { Complete regression in } 77 \% \text { of } \\
\mathrm{H} 1963 \text { and } 20 \% \text { in } \mathrm{H} 146\end{array}$ & Not tested & 51,56 \\
\hline DoHH2 human B-cell lymphoma & Xenograft & Morbidity delayed & Not tested & 51 \\
\hline MY5 multiple myeloma cell line & Xenograft & Complete regression & Not tested & 66 \\
\hline FDCP1-GFP- $\Delta$ Raf- $1^{\text {a }}$ promyeloid cells & Xenograft & Morbidity delayed & Not tested & 53 \\
\hline KG-1 acute myelogenous leukemia line & Xenograft & Morbidity delayed & Not tested & 53 \\
\hline Pre $B$ and IgM $^{+}$Iymphomas & $\begin{array}{l}\mathrm{E} \mu \text {-myc } \\
\text { transgenic and } \\
\mathrm{E} \mu \text {-myc/bcl-2 } \\
\text { double tg mice }\end{array}$ & Morbidity delayed & Not tested & 35 \\
\hline Acute lymphatic leukemia lines & Xenograft & Delayed progression & $\begin{array}{l}\text { Combined with } \\
V_{X L^{b}}\end{array}$ & 69 \\
\hline
\end{tabular}

${ }^{\mathrm{a}} \mathrm{A}$ constitutively active version of Raf- $1{ }^{\mathrm{b}} \mathrm{In}$ combination with vincristine, dexamethasone and L-asparaginase amidohydrase

by the interaction of tumor cells with bone marrow stroma cells, IGF-1 or IL-6 interfere with the effects of ABT-737. ${ }^{66,68}$

In childhood ALL, the $\mathrm{BH} 3$ mimetic efficiently synergized with L-asparaginase amidohydrolase (L-ASP) that depletes asparagines and glutamine in leukemic cells and vincristine in a panel of seven ALL cell lines tested. Interestingly, synergy with dexamethasone was only observed in 2/7 cell lines. ${ }^{69}$ Presumably, this reflects the status of a functional glucocorticoid receptor in this panel of cell lines or their ability to upregulate the GC receptor that has been shown to be rate limiting in GC-induced leukemia cell apoptosis. ${ }^{73}$ Importantly, ABT-737 was able to induce significant cell death in GC refractory cell lines and clinical studies including this $\mathrm{BH} 3$ mimetic in the initial GC monotherapy are warranted. Normal
PBMCs were not affected in their viability using the $\mathrm{BH} 3$ mimetic in combination with either L-ASP or vincristine. ${ }^{69}$

Taken together, these studies indicate that ABT-737 shows strong potency as a single agent against a variety of different lymphatic tumor types and that it may help to overcome drug resistance phenotypes when used in combination therapy. The latter observation also extends to epithelial tumors that, with few exceptions such as SCLC, proved relatively resistant to ABT-737 monotherapy.

ABT-737 activity in vivo. An important question was whether ABT-737 shows tumor cell toxicity in vivo without grossly affecting normal physiology (Table 2). Oltersdorf et al. $^{51}$ tested ABT-737 in a mouse xenograft model using 
H146 and H1963 SCLC cell lines. Single-agent therapy was started 30 days post-inoculation and ABT-737 caused complete regression of the established tumor xenografts within 20 days. Furthermore, tumors did only grow back in a low percentage of animals over the duration of the study. Tumor regression was due to apoptotic cell death, as indicated by caspase activity found in histological tumor sections as early as $2 \mathrm{~h}$ after the first treatment. Importantly, toxicity to normal mouse tissue was limited to short-term lymphopenia and thrombocytopenia that can be easily managed in the clinic. ${ }^{74,75}$ Morbidity caused by dissemination of DoHH2 human leukemia cells in SCID mice was also significantly delayed by ABT-737 treatment, but not by its enantiomer. ${ }^{51}$ In a xenotransplant model using the MY5 multiple myeloma line, application of the $\mathrm{BH} 3$ mimetic induced complete regression of established tumors as a daily-applied single agent. ${ }^{66}$ In vivo efficacy of ABT-737 was also tested in SCID mice that received FDC-P1 cells, transformed by a constitutively active from of the Raf- 1 protooncogene, or human KG-1 leukemia cells. Treatment of SCID mice carrying transplanted tumors resulted in a $50 \%$ decrease of tumor burden and in about twofold extended survival time. ${ }^{53}$ Similarly, ABT-737 delayed the progression of $c$-myc-driven mouse B-cell lymphomas and even those overexpressing $\mathrm{Bcl}-2 .{ }^{35}$ However, disease progression was only delayed but not prevented in these two models. Another convincing example of the putative in vivo efficacy of $A B T$ 737 comes from a study investigating its synergy with standard VXL (vincristine, dexamethasone and L-ASP) treatment in killing off pediatric ALL samples derived from treatment-refractory relapsed patients that were transplanted into NOD/SCID mice. The event-free survival was increased more than sixfold when compared to untreated control animals and this effect was further increased about twofold by $A B T-737$ when compared with mice treated with VXL alone. ${ }^{69}$

Taken together, ABT-737 is able to act potently as an anticancer agent against lymphoid as well as certain epithelial tumors in vivo, but will most likely not be sufficient to cure established neoplasias when used as a single agent. However, its potential to increase the efficacy of standard treatment protocols appears to be enormous and should help to reduce therapy-associated side effects significantly.

Resistance mechanisms: is it all just about Mcl-1?. As mentioned before, in certain tumor cell types the efficacy of ABT-737 appears to be limited (Table 1). A number of studies have investigated possible resistance mechanisms and all of them come to the same conclusion. Tumor cells that do not respond to the $\mathrm{BH} 3$ mimetic appear to display high levels of the Bcl-2 pro-survival homolog Mcl-1. ${ }^{35,53,56,58,64}$ In particular, solid tumors such as NSCLCs are responding very poorly to the ABT-737 compound in vitro. The basis of this phenomenon is not well investigated but tissue microarray analysis of tumor samples from chemotherapynaïve NSCLC patients revealed a correlation with high levels of $\mathrm{Mcl}-1 .{ }^{58}$ Since enforced expression of Noxa, which selectively targets $\mathrm{Mcl}-1$, restored sensitivity of NSCLC cells to ABT-737 in vitro, one may speculate that ABT-737 may kill solid tumors most effectively when combined with radiation therapy, which can trigger induction of Noxa, at least in the context of wild-type $p 53 .{ }^{76}$ Consistent with these observations, Lin et al. ${ }^{59}$ identified $\mathrm{Mcl}-1$ in an RNAi-based screen as the primary resistance factor in ABT-737insensitive $\mathrm{H} 196$ SCLC cells. Knock down of $\mathrm{Mcl}-1$ restored sensitivity of these cells but also proved effective in conferring sensitivity onto otherwise resistant colon or bladder cancer cell lines.

Mcl-1 expression also appears to protect non-malignant cells from ABT-737-mediated cytotoxicity. This is consistent with biochemical data demonstrating that $A B T-737$ does not bind to Mcl-1 (and A1). ${ }^{13} \mathrm{HeL}$ a and MCF-7 cells express high levels of $\mathrm{Mcl}-1$ and are highly resistant to ABT-737 treatment. Reduction of $\mathrm{Mcl}-1$ protein levels by various means such as shRNA, factor deprivation, the CDK2 inhibitor roscovitine or even DNA-damaging drugs increased apoptosis after ABT737 treatment. ${ }^{35}$ These results were interpreted in a manner that all Bcl-2 pro-survival proteins present in a given cell type, here $\mathrm{Bcl}-2$ and $\mathrm{Mcl}-1$, the latter not targeted by ABT-737, need to be restrained to free Bax and Bak to induce apoptosis. The indirect activation model (see Figure 1) suggests that Bak is activated only when it is displaced from both $\mathrm{Mcl}-1$ and $\mathrm{Bcl}-\mathrm{x}_{\mathrm{L}}$ by $\mathrm{BH} 3-$ only proteins. As ABT-737 has only low binding affinity to $\mathrm{Mcl}-1$, it cannot displace $\mathrm{Mcl}-1$ from Bak. In fact, this is not important in cells expressing only low levels of Mcl-1 or when a potent $\mathrm{Mcl}-1$ antagonist like Noxa is present, which facilitates ABT-737-induced apoptosis in MEFs. ${ }^{35}$ In line with these experiments, it was argued that expression levels of mcl-1 and also a 1 mRNA are low in most follicular lymphomas, CLL and SCLC tumor cells where ABT-737 shows singleagent efficacy. ${ }^{35,51}$ Interestingly, those SCLC lines that are less sensitive to the compound also display increased levels of $\mathrm{Mcl}-1$ expression. ${ }^{45}$ It has also been argued that high amounts of $\mathrm{Mcl}-1$ could suffice to sequester enough 'direct activators' to protect the cells from the apoptotic faith and that this phenomenon could also be accommodated in the 'direct activator' model ${ }^{77}$ (Figure 1). However, no experimental evidence supporting this hypothesis has been presented to date.

Konopleva et al. describe an alternative mechanism on how ABT-737 efficiency may be compromised. In OCl-AML3 acute leukemia cells, application of the MEK-1 inhibitor PD98059 showed strong synergistic effects with the $\mathrm{Bcl}-2$ inhibitor and this correlated with decreased $\mathrm{Mcl}-1$ protein levels, as previously reported, and also with decreased phosphorylation of $\mathrm{Bcl}-2$ in its unstructured loop. Employing site-directed mutagenesis they show that cells expressing Bcl-2 carrying phospho-site-inactivating alanine mutations are more sensitive to ABT-737 (and less Bax was found associated with $\mathrm{Bcl}-2$ in co-IP experiments), whereas replacement of the relevant serine/threonine residues by charged amino-acid residues rendered these cells more resistant to apoptosis. ${ }^{53}$

Since Bfl-1/A1 is also not bound efficiently by ABT-737 it will be interesting to investigate whether a correlation between the mimetic and $A 1$ expression exists in B-CLL, the only model where high $A 1$ levels was reported to contribute to drug resistance so far. $^{78}$ However, since $\mathrm{Bfl}-1 / \mathrm{A} 1$ expression appears to be highly restricted to few lymphocyte subsets its contribution to drug resistance phenotypes may be of limited clinical impact. 
In conclusion, these findings implicate that expression of $\mathrm{Mcl}-1$ is rate limiting for the efficacy of ABT-737 in tumor tissues, and $\mathrm{BH} 3$ mimetics or other compounds that target specifically $\mathrm{Mcl}-1$ may help overcome this limitation. However, since healthy cells also appear to depend on Mcl-1 for survival, combinatorial targeting of a broader range of prosurvival molecules also poses a significant threat to nonmalignant tissue. Therefore, the development of novel $\mathrm{BH} 3$ mimetics with distinct inhibition spectra targeting different combinations of Bcl-2 pro-survival family members may be a goal for the near future. Alternatively, selective inhibitors of individual $\mathrm{Bcl}-2$ pro-survival family members may even be more useful, since they could be freely combined to treat a broad range of tumors that differ strongly in their dependence on distinct $\mathrm{Bcl}-2$ homologs for survival.

ABT-263: the next generation. To provide more dosing flexibility, a Bcl-2 family inhibitor that is orally bioavailable was discovered at Abbott. This compound, ABT-263, displays subnanomolar binding to $\mathrm{Bcl}-2, \mathrm{Bcl}-\mathrm{x}_{\mathrm{L}}$ and $\mathrm{Bcl}-\mathrm{w}$ like ABT-737. Also, similar to ABT-737, the new compound shows single-agent efficacy on lymphomas, CLL and SCLC cell lines and potently synergizes with $\gamma$-irradiation and other cancer agents. As a single agent, ABT-263 regresses tumors (e.g. SCLC) in vivo and yields cures in some of the animal models. ${ }^{79}$ When combined with anticancer agents such as the proteasome inhibitor Velcade, the anti-CD20 antibody rituximab, or standard chemotherapy, ABT-263 is broadly active against a wide variety of tumors. Recently, ABT-263 has entered three phase I/IIA clinical trials for the treatment of patients suffering from lymphoma, CLL and SCLC. Although it is still early, responders have been identified in CLL patients. ${ }^{80}$ The side effects are those predicted by the preclinical studies and are likely mechanism based. For example, thrombocytopenia has been observed which is likely related to the inhibition of $\mathrm{BCl}-\mathrm{x}_{\mathrm{L}} .{ }^{69}$

\section{Prognostic Potential of BH3 Mimetics}

On the basis of the findings discussed above, expression levels of antiapoptotic Bcl-2 family members in cancer cells provide useful prognostic markers for the efficacy of ABT-737 and also provide a powerful tool to predict sensitivity to various chemotherapeutic agents.

Letai and co-workers ${ }^{64,65}$ introduced a strategy called $\mathrm{BH} 3$ profiling that aims to predict dependence of cancer cells on individual antiapoptotic proteins for survival and, therefore, indirectly also sensitivity to ABT-737. The principle of this assay is to isolate mitochondria from tumor cells and incubate them with a panel of $\mathrm{BH} 3$ peptides to determine subsequent cytochrome $c$ release. This method has the potential to predict sensitivity of tumor cells to the Abbott compound as a single agent since ABT-737 only triggers efficient cytochrome $c$ release in cells that depend on $\mathrm{Bcl}-2$ for survival but not in those that depend on $\mathrm{Mcl}-1$. This assay system may have some merit in predicting the intrinsic responsiveness of tumor cells to different $\mathrm{BH} 3$ mimetics in the near future, and may help to decide which mimetic should be used in putative future combination treatment regimens. Whether it will allow a prognosis on the in vivo responsiveness of certain tumors to conventional anticancer agents, as proposed by the authors, remains questionable. The authors suggested that tumor cells 'primed for death,' for example, those that show Bcl-2 in complex with Bim and therefore are sensitive to 'sensitizer' $\mathrm{BH} 3$ peptides (e.g. a Bad $\mathrm{BH} 3$ peptide) in the $\mathrm{BH} 3$ profiling assay, would be more responsive to anticancer agents as 'unprimed' tumor cells. ${ }^{65}$ In this study, 'unprimed' tumor cells did not show detectable levels of Bim associated with Bcl-2 and were only susceptible to 'direct activator' Bim- or Bidbased $\mathrm{BH} 3$ peptides. The severe caveat of this study is, however, that only one 'unprimed' model cell line was investigated and it responded very similar to adriamycin, etoposide or vincristine, as at least one out of the five 'primed' cell lines tested. ${ }^{65}$ So the prediction that tumor cells need to be in a 'primed state' to undergo drug-induced apoptosis appears to be premature. More experimental evidence and investigations of additional tumor model systems, besides follicular lymphoma and DLBL, are needed to prove or disprove the usefulness and general validity of the $\mathrm{BH}$-profiling concept.

\section{Conclusions}

On the basis of the detailed knowledge on how apoptosis is regulated at the molecular level, much progress has been made over the last couple of years to target specific components of the apoptosis machinery for anticancer therapy. Three major concepts emerge and are currently translated into clinical application. Activation of DRs such as TRAIL-R by recombinant ligand or agonistic antibodies and suppression of IAP mediated caspase inactivation as well as direct activation of the proapototic Bcl-2 family members Bax and Bak by small molecule drugs. It is time now to evaluate their suitability for the treatment of distinct malignant disease in humans as well as their long-term clinical applicability and merits.

Acknowledgements. The work in our laboratory is supported by fellowships and grants from the FWF (Austrian Science Fund): Y212-B13 START, the Doctoral College MCBO, the SFB021, as well as by the Association for International Cancer Research (AICR), EU-FP6, the Innsbruck Medical University (IFTZ) and the Tyrolean Science Fund (TWF). We are grateful to our colleagues, especially A Strasser, G Häcker and S Fesik for many interesting discussions and sharing unpublished results as well as to all members of the SFB021 (Proliferation and Cell Death in Tumors) for their input into our research. We apologize to the many scientists in this field whose excellent research was not cited but was only referred to indirectly through reviews.

1. Adams JM, Cory S. The Bcl-2 apoptotic switch in cancer development and therapy. Oncogene 2007; 26: 1324-1337.

2. Vaux DL, Cory S, Adams JM. Bcl-2 gene promotes haemopoietic cell survival and cooperates with c-myc to immortalize pre-B cells. Nature 1988; 335: 440-442.

3. Youle RJ, Strasser A. The BCL-2 protein family: opposing activities that mediate cell death. Nat Rev Mol Cell Biol 2008; 9: 47-59.

4. Fesik SW. Promoting apoptosis as a strategy for cancer drug discovery. Nat Rev Cancer 2005; 5: 876-885.

5. Kassahn D, Nachbur U, Brunner T. CD95 L pro-drug: a novel Swiss Army knife in cancer therapy? Cell Death Differ 2007; 14: 393-394.

6. Vucic D, Fairbrother WJ. The inhibitor of apoptosis proteins as therapeutic targets in cancer. Clin Cancer Res 2007; 13: 5995-6000.

7. Petersen SL, Wang L, Yalcin-Chin A, Li L, Peyton M, Minna J et al. Autocrine TNFalpha signaling renders human cancer cells susceptible to Smac-mimetic-induced apoptosis. Cancer Cell 2007; 12: 445-456.

8. Varfolomeev E, Blankenship JW, Wayson SM, Fedorova AV, Kayagaki N, Garg P et al. IAP antagonists induce autoubiquitination of C-IAPs, NF-kappaB activation, and TNFalphadependent apoptosis. Cell 2007; 131: 669-681. 
9. Vince JE, Wong WW, Khan N, Feltham R, Chau D, Ahmed AU et al. IAP antagonists target CIAP1 to induce TNFalpha-dependent apoptosis. Cell 2007; 131: 682-693.

10. Zong WX, Lindsten T, Ross AJ, MacGregor GR, Thompson CB. BH3-only proteins that bind pro-survival $\mathrm{Bcl}-2$ family members fail to induce apoptosis in the absence of $\mathrm{Bax}$ and Bak. Genes Dev 2001; 15: 1481-1486

11. Lindsten T, Ross AJ, King A, Zong WX, Rathmell JC, Shiels HA et al. The combined functions of proapoptotic Bcl-2 family members Bak and Bax are essential for normal development of multiple tissues. Mol Cell 2000; 6: 1389-1399.

12. Willis SN, Adams JM. Life in the balance: how BH3-only proteins induce apoptosis. Curr Opin Cell Biol 2005; 17: 617-625.

13. Chen L, Willis SN, Wei A, Smith BJ, Fletcher JI, Hinds MG et al. Differential targeting of prosurvival $\mathrm{Bcl}-2$ proteins by their $\mathrm{BH} 3$-only ligands allows complementary apoptotic function. Mol Cell 2005; 17: 393-403.

14. Willis SN, Fletcher JI, Kaufmann T, van Delft MF, Chen L, Czabotar PE et al. Apoptosis initiated when BH3 ligands engage multiple Bcl-2 homologs, not Bax or Bak. Science 2007; 315: $856-859$

15. Letai A, Bassik M, Walensky L, Sorcinelli M, Weiler S, Korsmeyer S. Distinct BH3 domains either sensitize or activate mitochondrial apoptosis, serving as prototype cancer therapeutics. Cancer Cell 2002; 2: 183.

16. Kuwana T, Bouchier-Hayes L, Chipuk JE, Bonzon C, Sullivan BA, Green DR et al. BH3 domains of BH3-only proteins differentially regulate Bax-mediated mitochondrial membrane permeabilization both directly and indirectly. Mol Cell 2005; 17: 525-535.

17. Kim R, Emi M, Matsuura K, Tanabe K. Antisense and nonantisense effects of antisense $\mathrm{Bcl}-2$ on multiple roles of Bcl-2 as a chemosensitizer in cancer therapy. Cancer Gene Ther 2007: 14: 1-11.

18. Rudin CM, Kozloff M, Hoffman PC, Edelman MJ, Karnauskas R, Tomek R et al. Phase study of G3139, a bcl-2 antisense oligonucleotide, combined with carboplatin and etoposide in patients with small-cell lung cancer. J Clin Oncol 2004; 22: 1110-1117.

19. Tolcher AW, Chi K, Kuhn J, Gleave M, Patnaik A, Takimoto $C$ et al. A phase II, pharmacokinetic, and biological correlative study of oblimersen sodium and docetaxel in patients with hormone-refractory prostate cancer. Clin Cancer Res 2005; 11: 3854-3861.

20. Margolin K, Synold TW, Lara P, Frankel P, Lacey SF, Quinn DI et al. Oblimersen and alpha-interferon in metastatic renal cancer: a phase II study of the California Cance Consortium. J Cancer Res Clin Oncol 2007; 133: 705-711.

21. Moore J, Seiter K, Kolitz J, Stock W, Giles F, Kalaycio M et al. A phase II study of Bcl-2 antisense (oblimersen sodium) combined with gemtuzumab ozogamicin in older patients with acute myeloid leukemia in first relapse. Leuk Res 2006; 30: 777-783.

22. Waters JS, Webb A, Cunningham D, Clarke PA, Raynaud F, di Stefano F et al. Phase clinical and pharmacokinetic study of bcl-2 antisense oligonucleotide therapy in patients with non-Hodgkin's lymphoma. J Clin Oncol 2000; 18: 1812-1823.

23. O'Brien S, Moore JO, Boyd TE, Larratt LM, Skotnicki A, Koziner B et al. Randomized phase III trial of fludarabine plus cyclophosphamide with or without oblimersen sodium (Bcl-2 antisense) in patients with relapsed or refractory chronic lymphocytic leukemia. J Clin Oncol 2007; 25: 1114-1120.

24. Chanan-Khan AA. Bcl-2 antisense therapy in multiple myeloma. Oncology 2004; 18: 21-24.

25. Bedikian AY, Millward M, Pehamberger H, Conry R, Gore M, Trefzer U et al. Bcl-2 antisense (oblimersen sodium) plus dacarbazine in patients with advanced melanoma: the Oblimersen Melanoma Study Group. J Clin Oncol 2006; 24: 4738-4745.

26. Olie RA, Hall J, Natt F, Stahel RA, Zangemeister-Wittke U. Analysis of ribosyl-modified, mixed backbone analogs of a bcl-2/bcl-xL antisense oligonucleotide. Biochim Biophys Acta 2002; 1576: 101-109.

27. Reed JC, Pellecchia M. Apoptosis-based therapies for hematologic malignancies. Blood 2005; 106: 408-418.

28. Tzung SP, Kim KM, Basanez G, Giedt CD, Simon J, Zimmerberg J et al. Antimycin A mimics a cell-death-inducing Bcl-2 homology domain 3. Nat Cell Biol 2001; 3: 183-191.

29. Chan SL, Lee MC, Tan KO, Yang L-K, Lee ASY, Flotow $\mathrm{H}$ et al. Identification of chelerythrine as an inhibitor of BcIXL function. J Biol Chem 2003; 278: 20453-20456.

30. Withers WA, Carruth FE. Gossypol - a toxic substance in cottonseed. A preliminary note. Science 1915; 41: 324

31. Becattini B, Kitada S, Leone M, Monosov E, Chandler S, Zhai D et al. Rational design and real time, in-cell detection of the proapoptotic activity of a novel compound targeting Bcl-X(L). Chem Biol 2004; 11: 389-395.

32. Enyedy IJ, Ling $Y$, Nacro K, Tomita $Y$, Wu X, Cao $Y$ et al. Discovery of small-molecule inhibitors of Bcl-2 through structure-based computer screening. J Med Chem 2001; 44 4313-4324.

33. Wang JL, Liu D, Zhang ZJ, Shan S, Han X, Srinivasula SM et al. Structure-based discovery of an organic compound that binds Bcl-2 protein and induces apoptosis of tumor cells. Proc Natl Acad Sci USA 2000; 97: 7124-7129.

34. Degterev A, Lugovskoy A, Cardone M, Mulley B, Wagner G, Mitchison T et al. Identification of small-molecule inhibitors of interaction between the $\mathrm{BH} 3$ domain and $\mathrm{Bcl}-\mathrm{x}_{\mathrm{L}}$. Nat Cell Biol 2001; 3: 173-182.

35. van Delft MF, Wei AH, Mason KD, Vandenberg CJ, Chen L, Czabotar PE et al. The BH3 mimetic ABT-737 targets selective Bcl-2 proteins and efficiently induces apoptosis via Bak/ Bax if Mcl-1 is neutralized. Cancer Cell 2006; 10: 389-399.

36. Lickliter JD, Wood NJ, Johnson L, McHugh G, Tan J, Wood F et al. HA14-1 selectively induces apoptosis in Bcl-2-overexpressing leukemia/lymphoma cells, and enhances cytarabine-induced cell death. Leukemia 2003; 17: 2074-2080.
37. Zhang M, Liu H, Tian Z, Griffith BN, Ji M, Li QQ. Gossypol induces apoptosis in human PC-3 prostate cancer cells by modulating caspase-dependent and caspase-independent cell death pathways. Life Sci 2007; 80: 767-774.

38. Kessel D, Reiners Jr JJ. Initiation of apoptosis and autophagy by the $\mathrm{Bcl}-2$ antagonist HA14-1. Cancer Lett 2007; 249: 294-299.

39. Schwartz PS, Manion MK, Emerson CB, Fry JS, Schulz CM, Sweet IR et al. 2-Methoxy antimycin reveals a unique mechanism for $\mathrm{Bcl}-\mathrm{x}(\mathrm{L})$ inhibition. Mol Cancer Ther 2007; 6 : 2073-2080.

40. Walensky LD, Kung AL, Escher I, Malia TJ, Barbuto S, Wright RD et al. Activation of apoptosis in vivo by a hydrocarbon-stapled BH3 helix. Science 2004; 305: 1466-1470.

41. Walensky LD, Pitter K, Morash J, Oh KJ, Barbuto S, Fisher J et al. A stapled BID BH3 helix directly binds and activates BAX. Mol Cell 2006; 24: 199-210.

42. Labi V, Erlacher M, Kiessling S, Villunger A. BH3-only proteins in cell death initiation, malignant disease and anticancer therapy. Cell Death Differ 2006; 13: 1325-1338.

43. Kutzki O, Park HS, Ernst JT, Orner BP, Yin H, Hamilton AD. Development of a potent Bcl$\mathrm{x}(\mathrm{L})$ antagonist based on alpha-helix mimicry. J Am Chem Soc 2002; 124: 11838-11839.

44. Wang G, Nikolovska-Coleska Z, Yang CY, Wang R, Tang G, Guo J et al. Structure-based design of potent small-molecule inhibitors of anti-apoptotic Bcl-2 proteins. J Med Chem 2006; 49: 6139-6142.

45. Shoemaker AR, Oleksijew A, Bauch J, Belli BA, Borre T, Bruncko M et al. A small-molecule inhibitor of $\mathrm{Bcl}-\mathrm{XL}$ potentiates the activity of cytotoxic drugs in vitro and in vivo. Cancer Res 2006; 66: 8731-8739.

46. Perez-Galan P, Roue G, Villamor N, Campo E, Colomer D. The BH3-mimetic GX15-070 synergizes with bortezomib in mantle cell lymphoma by enhancing Noxa-mediated activation of Bak. Blood 2007; 109: 4441-4449.

47. Li J, Viallet J, Haura EB. A small molecule pan-Bcl-2 family inhibitor, GX15-070, induces apoptosis and enhances cisplatin-induced apoptosis in non-small cell lung cancer cells. Cancer Chemother Pharmacol 2007; 61: 525-534.

48. Trudel S, Li ZH, Rauw J, Tiedemann RE, Wen XY, Stewart AK. Preclinical studies of the panBcl inhibitor obatoclax (GX015-070) in multiple myeloma. Blood 2007; 109: 5430-5438.

49. Mohammad RM, Goustin AS, Aboukameel A, Chen B, Banerjee S, Wang G et al. Preclinical studies of TW-37, a new nonpeptidic small-molecule inhibitor of Bcl-2, in diffuse large cell lymphoma xenograft model reveal drug action on both Bcl-2 and Mcl-1. Clin Cancer Res 2007; 13: 2226-2235.

50. Verhaegen M, Bauer JA, Martin de la Vega C, Wang G, Wolter KG, Brenner JC et al. A novel $\mathrm{BH} 3$ mimetic reveals a mitogen-activated protein kinase-dependent mechanism of melanoma cell death controlled by p53 and reactive oxygen species. Cancer Res 2006; 66 : 11348-11359.

51. Oltersdorf T, Elmore SW, Shoemaker AR, Armstrong RC, Augeri DJ, Belli BA et al. An inhibitor of Bcl-2 family proteins induces regression of solid tumours. Nature 2005; 435: 677-681.

52. Wojciechowski S, Tripathi P, Bourdeau T, Acero L, Grimes HL, Katz JD et al. Bim/Bcl-2 balance is critical for maintaining naive and memory T cell homeostasis. J Exp Med 2007; 204: $1665-1675$.

53. Konopleva M, Contractor R, Tsao T, Samudio I, Ruvolo PP, Kitada S et al. Mechanisms of apoptosis sensitivity and resistance to the $\mathrm{BH} 3$ mimetic ABT-737 in acute myeloid leukemia. Cancer Cell 2006; 10: 375-388.

54. Del Gaizo Moore V, Brown JR, Certo M, Love TM, Novina CD, Letai A. Chronic lymphocytic leukemia requires $B C L 2$ to sequester prodeath $B I M$, explaining sensitivity to BCL2 antagonist ABT-737. J Clin Invest 2007; 117: 112-121.

55. Maiuri MC, Le Toumelin G, Criollo A, Rain JC, Gautier F, Juin P et al. Functional and physical interaction between $\mathrm{Bcl}-\mathrm{X}(\mathrm{L})$ and a BH3-like domain in Beclin-1. EMBO J 2007; 26: 2527-2539.

56. Tahir SK, Yang X, Anderson MG, Morgan-Lappe SE, Sarthy AV, Chen J et al. Influence of Bcl-2 family members on the cellular response of small-cell lung cancer cell lines to ABT-737. Cancer Res 2007; 67: 1176-1183.

57. Cragg MS, Kuroda J, Puthalakath $H$, Huang DC, Strasser A. Gefitinib-induced killing of NSCLC cell lines expressing mutant EGFR requires BIM and can be enhanced by $\mathrm{BH} 3$ mimetics. PLoS Med 2007; 4: 1681-1689; discussion 1690

58. Wesarg E, Hoffarth S, Wiewrodt R, Kröll M, Biesterfeld S, Huber C et al. Targeting BCL-2 family proteins to overcome drug resistance in non-small cell lung cancer. Int $\mathrm{J}$ Cance 2007; 121: 2387-2394.

59. Lin X, Morgan-Lappe S, Huang X, Li L, Zakula DM, Vernetti LA et al. 'Seed' analysis of off-target siRNAs reveals an essential role of $\mathrm{Mcl}-1$ in resistance to the small-molecule Bcl2/Bcl-XL inhibitor ABT-737. Oncogene 2007; 26: 3972-3979.

60. Kohl TM, Hellinger C, Ahmed F, Buske C, Hiddemann W, Bohlander SK et al. BH3 mimetic ABT-737 neutralizes resistance to FLT3 inhibitor treatment mediated by FLT3-independent expression of BCL2 in primary AML blasts. Leukemia 2007; 21: 1763-1772.

61. Chen S, Dai Y, Harada H, Dent P, Grant S. Mcl-1 down-regulation potentiates ABT-737 lethality by cooperatively inducing Bak activation and Bax translocation. Cancer Res 2007; 67: 782-791.

62. Kuroda J, Puthalakath H, Cragg MS, Kelly PN, Bouillet P, Huang DC et al. Bim and Bad mediate imatinib-induced killing of $\mathrm{Bcr} / \mathrm{Abl}+$ leukemic cells, and resistance due to their loss is overcome by a BH3 mimetic. Proc Natl Acad Sci USA 2006; 103: 14907-14912.

63. Kuroda J, Kimura S, Strasser A, Andreeff M, O'Reilly LA, Ashihara E et al. Apoptosis-based dual molecular targeting by INNO-406, a second-generation Bcr-Abl inhibitor, and ABT737, an inhibitor of antiapoptotic Bcl-2 proteins, against Bcr-Abl-positive leukemia. Cell Death Differ 2007; 14: 1667-1677. 
64. Certo M, Moore Vdel G, Nishino M, Wei G, Korsmeyer S, Armstrong SA et al. Mitochondria primed by death signals determine cellular addiction to antiapoptotic BCL-2 family members. Cancer Cell 2006; 9: 351-365.

65. Deng J, Carlson N, Takeyama K, Dal Cin P, Shipp M, Letai A. BH3 profiling identifies three distinct classes of apoptotic blocks to predict response to ABT-737 and conventiona chemotherapeutic agents. Cancer Cell 2007; 12: 171-185.

66. Trudel S, Stewart AK, Li Z, Shu Y, Liang SB, Trieu Y et al. The Bcl-2 family protein inhibitor ABT-737, has substantial antimyeloma activity and shows synergistic effect with dexamethasone and melphalan. Clin Cancer Res 2007; 13: 621-629.

67. Kline MP, Rajkumar SV, Timm MM, Kimlinger TK, Haug JL, Lust JA et al. ABT-737, an inhibitor of Bcl-2 family proteins, is a potent inducer of apoptosis in multiple myeloma cells. Leukemia 2007; 21: 1549-1560.

68. Chauhan D, Velankar M, Brahmandam M, Hideshima T, Podar K, Richardson P et al. A novel $\mathrm{Bcl}-2 / \mathrm{Bcl}-\mathrm{X}(\mathrm{L}) / \mathrm{Bcl}-\mathrm{w}$ inhibitor $\mathrm{ABT}-737$ as therapy in multiple myeloma. Oncogene 2007; 26: 2374-2380.

69. Kang MH, Kang YH, Szymanska B, Wilczynska-Kalak U, Sheard MA, Harned TM et al. Activity of vincristine, L-ASP, and dexamethasone against acute lymphoblastic leukemia is enhanced by the BH3-mimetic ABT-737 in vitro and in vivo. Blood 2007; 110: 2057-2066.

70. Dai Y, Rahmani M, Corey SJ, Dent P, Grant S. A Bcr/Abl-independent, Lyn-dependent form of imatinib mesylate (STI-571) resistance is associated with altered expression of Bcl2. J Biol Chem 2004; 279: 34227-34239.

71. Gong Y, Somwar R, Politi K, Balak M, Chmielecki J, Jiang X et al. Induction of bim is essential for apoptosis triggered by EGFR kinase inhibitors in mutant EGFR-dependent lung adenocarcinomas. PLoS Med 2007; 4: e294.
72. She $\mathrm{QB}$, Solit $\mathrm{DB}, \mathrm{Ye} \mathrm{Q}$, O'Reilly KE, Lobo J, Rosen $\mathrm{N}$. The BAD protein integrates survival signaling by EGFR/MAPK and PI3K/Akt kinase pathways in PTEN-deficient tumor cells. Cancer Cell 2005; 8: 287-297.

73. Schmidt S, Rainer J, Ploner C, Presul E, Riml S, Kofler R. Glucocorticoid-induced apoptosis and glucocorticoid resistance: molecular mechanisms and clinical relevance. Cell Death Differ 2004; 11 (Suppl 1): S45-S55.

74. Zhang H, Nimmer PM, Tahir SK, Chen J, Fryer RM, Hahn KR et al. Bcl-2 family proteins are essential for platelet survival. Cell Death Differ 2007; 14: 943-951.

75. Mason KD, Carpinelli MR, Fletcher Jl, Collinge JE, Hilton AA, Ellis S et al. Programmed anuclear cell death delimits platelet life span. Cell 2007; 128: 1173-1186.

76. Oda E, Ohki R, Murasawa H, Nemoto J, Shibue T, Yamashita T et al. Noxa, a BH3-only member of the bcl-2 family and candidate mediator of p53-induced apoptosis. Science 2000; 288: 1053-1058.

77. Letai A. BCL-2: found bound and drugged!. Trends Mol Med 2005; 11: 442-444.

78. Olsson A, Norberg M, Okvist A, Derkow K, Choudhury A, Tobin G et al. Upregulation of bfl1 is a potential mechanism of chemoresistance in B-cell chronic lymphocytic leukaemia. $\mathrm{Br}$ J Cancer 2007; 97: 769-777.

79. Lock R, Carol H, Houghton PJ, Morton CL, Kolb EA, Gorlick R et al. Initial testing (stage 1) of the $\mathrm{BH} 3$ mimetic ABT-263 by the pediatric preclinical testing program. Pediatr Blood Cancer 2007 [e-pub ahead of print].

80. Wyndham H, Wilson AT, Levine AM, Dunleavy K, Krivoshik AP, Hagey AE et al. A phase 1/ 2a study evaluating the safety, pharmacokinetics, and efficacy of ABT-263 in subjects with refractory or relapsed lymphoid malignancies. Session Type: Poster Session, Board no. 525-I. ASH Meeting Abstracts 2007. 